低速電子回折法の動力学的解析による $\operatorname{Ir}(111)$ 清浄表面 および水素吸着表面構造の研究*

松本 益明*1 · 小倉 正平*1 ·福谷 克之*1 ·岡野 達雄 $* 1$. 岡田美智雄 $* 2$

\title{
Dynamical Low-energy Electron Diffraction Analyses of Clean and H-adsorbed $\operatorname{Ir}(111)$ Surfaces
}

Masuaki MATSUMOTO*1, Syohei OGURA*1, Katsuyuki FUKUTANI*1, Tatsuo OKANO*1 and Michio OKADA*2

\author{
*1 Institute of Industrial Science, University of Tokyo, 4-6-1 Komaba, Meguro-ku, Tokyo 153-8505, Japan \\ *2Department of Chemistry, Graduate School of Science, Osaka University, \\ 1-1 Machikaneyama-cho, Toyonaka, Osaka 560-0043, Japan
}

(Received November 24, 2005, Accepted January 14, 2006)

\begin{abstract}
Structures of Clean and H-adsorbed $\operatorname{Ir}(111)$ surfaces were studied by dynamical analyses of low-energy electron diffraction (LEED). LEED pattern for the Clean $\operatorname{Ir}(111)$ surface was $1 \times 1$. Dynamical analysis of LEED spot intensity vs incident electron enegy $(I-V)$ curves for the clean $\operatorname{Ir}(111)$ surface revealed that the layer distance between the 1 st and the 2nd layers $\left(d_{12}\right)$ equals to $0.2207 \pm$ $0.002 \mathrm{~nm}$, which is almost equal to the bulk value $(0.2217 \mathrm{~nm})$. It appears that our result contradicts an previous report, which concluded that $d_{12}$ equals to $0.216 \mathrm{~nm}$ which is $2.6 \%$ smaller than the bulk value. However their error bar was so large $( \pm 0.01 \mathrm{~nm})$ that it is suggested that our result is the accurate atomic structure of the clean $\operatorname{Ir}(111)$ surface. LEED pattern was almost unchanged by $\mathrm{H}$ adsorption of $1 \mathrm{ML}\left(1.56 \times 10^{15} \mathrm{~cm}^{-2}\right)$ at $80 \mathrm{~K}$. The difference between LEED $I-V$ curves before and after hydrogen adsorption was very small and it was impossible to determine the adsorption structure on $\operatorname{Ir}(111)$ but it can be conculded that no reconstruction occurs and only a very small relaxation occurs by the adsorption of hydrogen on $\operatorname{Ir}(111)$ surface.
\end{abstract}

\section{1. はじめに}

水素は遷移金属表面で解離吸着し, 配位数の多いサイト, つまり(111)表面では 3 配位の hollow site（Fig. $3(\mathrm{~g})$ 参照） に吸着する傾向があるが， $\operatorname{Ir}(111)$ にいては, Hagedorn らは高分解能電子損失分光法 (HREELS) の実験結果から, 低被覆率では水素が非局在化し, 高被覆率においては 1 配 位の ontop site に吸着すると報告して抢り1)，中西らは第一 原理計算を用いてやはり ontop site への吸着が fcc hollow site よりも安定であると報告する2)など，特異的である可能 性がある. 本報告において, 我々は原子構造の決定に最適な 低速電子回折法 (LEED) の回折点強度の入射電子エネルギー 依存性 $(I-V$ 曲線) の動力学的解析を用いて $\operatorname{Ir}(111)$ の水素 吸着表面についての構造解析を試みた. 水素による電子の散 乱は非常に小さいため, 水素位置の確定はかなり困難である と予想されるが，水素の吸着は基板原子の緩和や再構成を伴 う場合が多く, 間接的ながら水素の吸着構造に関する情報を 得ることは可能であり, 最近では $\mathrm{W}(110)^{3)}, \mathrm{Ni}(111)^{4)}$ や Ir $(100)^{5,6)}$ 等への吸着に関する報告がある. 水素による基板の 変化を正確に求めるためには，まず清浄表面の構造解析に高 い精度が必要である. $\operatorname{Ir}(111)$ 清浄表面の構造解析は1970年 代にChan らによりなされているが，彼らの解析は異なる入 射角での鏡面反射点の $I-V$ 曲線のみを使用しており，精度 が $0.01 \mathrm{~nm}$ とあまり良くないものであった7)。そこで，ま ず清浄表面の構造について高精度の解析を行った後, 水素吸 着による影響を調べた。

* 平成17年11月 9 日 第46回真空に関する連合講演会で発表

\section{2. 実験および計算方法}

実験はベース圧力 $7 \times 10^{-9} \mathrm{~Pa}$ の超高真空中で行った. Ir (111) 試料（5 mm 角, 厚さ $2 \mathrm{~mm})$ の清浄化は約 $1 \times 10^{-5}$ $\mathrm{Pa}$ の酸素雲囲気中に挍いて約 $1050 \mathrm{~K}$ で 5-7 分間アニールし た後, 酸素を排気して $10^{-7} \mathrm{~Pa}$ 台の圧力において約 1 分間 $1500 \mathrm{~K}$ でフラッシングするという処理を数十回繰返すこと により行った. 表面の清浄さは LEED パターンで確認した. LEEDの測定と水素の吸着は, 約 $80 \mathrm{~K}$ の試料温度で行っ た. 水素の吸着は真空容器を約 $2.66 \times 10^{-4} \mathrm{~Pa}$ の圧力の水素 ガスで約 500 秒満たすことにより（曝露量 $1000 \mathrm{~L} （ 1 \mathrm{~L}=$ $\left.\left.1.33 \times 10^{-4} \mathrm{~Pa} \cdot \mathrm{s}\right)\right)$ 行った. これは別の真空容器における昇 温脱離法（TDS）抢よび核反応法（NRA）の測定で， $80 \mathrm{~K}$ で1000 L 曝露することにより, 水素は吸収されずに表面に 被覆率 $1 \mathrm{ML}\left(1.56 \times 10^{15} \mathrm{~cm}^{-2}\right)$ で飽和吸着し, 水素ガス排 気後も実験に必要な数十分程度の時間では被覆率がほとんど 変化しないという結果が得られたことに合わせたためであ $3^{8,9)}$. パーソナルコンピューター (PC) で LEED 制御電源 と冷却 CCD カメラを制御し, 入射電子エネルギーを $50 \mathrm{eV}$ から516 eVの範囲で約 $2 \mathrm{eV}$ の間隔でLEED パターンを自 動的に撮影および保存した. 清浄表面と水素吸着表面との実 験条件をできるだけ合わせるために, 水素曝露の前後で試 料, LEED 光学系及び CCD カメラは固定したままとし, エ ミッション電流などの条件もできるだけ同一にして測定を行 った. 実験終了後, 保存されたパターンから信頼できるエネ ルギー範囲のみについて回折点強度の測定とバックグラウン ドの除去を行って $I-V$ 曲線を抽出した. $\operatorname{Ir}(111)$ 清浄表面及 び水素吸着表面の LEED パターンはどちらも $1 \times 1$ で, 抽出 
した $I-V$ 曲線は $(1,0),(0,1),(1,1),(2,0),(0,2)$ の 5 本 であり，それぞれ等価な回折点の信頼できる領域の平均をと った上で，さらにフーリエ変換を利用して高周波成分を除去 する形で平滑化を行った。

動力学的な解析には英国ケンブリッジ大学の G. Held ら により開発されたCLEEDパッケージを用いた10)。これ は，一般に多く使われている M. A. Van Hove らの Symmetrized Automated Tensor (SAT) LEED package ${ }^{11)}$ と異なり, $\mathrm{C}$ 言語で書かれて抢り，比較的取扱いが容易である。 またテ ソソル法を用いず, 完全に動力学的な計算のみで実験結果と 計算結果の比較因子（ $R$-factor）が極小となる構造を自動的 に探索するプログラムとなっている. 垂直入射条件が満たさ れていない場合にも比較的容易に $I-V$ 曲線の計算が可能で あり，撮影時の電子ビームの垂直入射条件については，等価 な $I-V$ 曲線ができるだけ同じピーク位置を持つように調整 したが, 動力学的解析で最適化した結果, 垂直から約 0.75 度 傾いていたことがわかった. パッケージは動力学的計算, I$V$ 比較, 最適構造自動探索の 3 つのプログラムから構成さ れており，独立して実行可能である.コンパイルと実行には UNIX が必要だが，通常のPC上の Linux や Microsoft Windows 上に UNIX 環境を構築可能な Cygwin 等でも可能 である. 最近は PCの性能が向上したため, 数年前のワーク ステーションよりも安価かつ高速に計算でき, 今回のように 単位格子が小さく, パラメータ数の少ない系では数十秒で動 力学的計算が可能であった. しかし自動探索には動力学的計 算を数十回から数百回繰り返す必要があるため, 数十分から 数時間を必要とした.

重い元素の場合には相対論の効果が現れるため $100 \mathrm{eV}$ 以 下のエネルギー領域を使用しないことが勧められてお り ${ }^{11)}$, 逆に高エネルギーの領域ではバックグラウンドが高 くなり正確な回折点強度が得られないと考えたため, 最大で 100-450 eVのエネルギー範囲のみを計算に使用した． $R$ factorにはPendryにより提唱されているもの $\left(R_{\mathrm{p}}\right)$ を用い た ${ }^{12)}$. 全エネルギー範囲, Pendry のダブル $R$-factor $(R R)$ は，清浄表面と水素吸着表面でそれぞれ $1390 \mathrm{eV}, 0.1516$ と $1230 \mathrm{eV}, 0.1649$ であった。これとパラメータを一つだけ変 化させたときの $R_{\mathrm{p}}$ の変化の様子（パラメータスキャン）か ら， $R_{\mathrm{p}}$ の最小值 $R_{\min }$ を用いて $R_{\mathrm{p}}<R_{\min } \times(1+R R)$ で誤差を 評価した ${ }^{12)}$. 今回の動力学的な計算で用いたフェーズシフ トはV Van Hove らのプログラムを用いて計算し11), 各原子 に対して 9 個 $\left(l_{\max }=8\right)$ を用いた。この数は部分波の数に 対応し, 多いほど計算精度が上がるが, 計算時間も急激に増 大するため, 部分波の数による誤差が上記の誤差の範囲内に 十分入る值として決めた. ポテンシャルの実部は固体内部で の電子のエネルギーを左右し， $I-V$ 曲線のピーク位置をシフ トさせるため, 最適化の過程で変化させた。 虚部は電子の減 衰を表し, 主に $I-V$ 曲線のピークの幅を決める。これは事 前の計算では $-4 \mathrm{eV}$ から $-6 \mathrm{eV}$ の範囲で上記の䛊差内に十 分入った. 本研究ではー $4.5 \mathrm{eV}$ を用いた. Ir と $\mathrm{H}$ のデバイ 温度はそれぞれ $420 \mathrm{~K}$ と $105 \mathrm{~K}$ とし, 表面とバルクで同じ值 を用いた、デバイ温度は原子の熱的な振動を反映しており, 表面とバルクでも異なっているため, 表面原子のデバイ温度
を評価するためには LEED 回折点強度の温度依存性を測定 する必要がある。しかしながら $I-V$ 曲線のピーク位置への 影響は小さいため構造解析への影響は小さい. 事前の計算で は $150 \mathrm{~K}$ から $600 \mathrm{~K}$ の範囲で上記の誤差の範囲に十分収まっ ていたため, 理科年表に記載されていたバルクの值を用い た ${ }^{13)}$.

\section{3. 実験および計算結果と考察}

Fig. 1 に清浄表面（実線）と1000 L の水素曝露後（破線） の LEEDの $I-V$ 曲線を示す。一見して分かるように曝露前 後での $I-V$ 曲線の変化は非常に小さい。そこで我々はまず 清浄表面の構造決定を行い, その最適構造での計算結果を水 素吸着表面での実験で得られた $I-V$ 曲線と比較することに より,このような微小な $I-V$ 曲線の相違がぞの程度構造の 違いを反映しているかを調べた.

Ir は格子定数 $0.384 \mathrm{~nm}$ の面心立方格子であるため, 清浄 表面の初期条件ではすべての層間距離をバルクと同じ 0.2217 $\mathrm{nm}$ とした. また, LEED パターンは $1 \times 1$ のみが観察され るため, 垂直方向の原子層間距離の緩和のみが起きると仮定 した。構造解析で变化させたパラメータは第 1-2 層間距離 $\left(d_{12}\right)$ ，第 2-3 層間距離 $\left(d_{23}\right)$ ，第 3-4 層間距離 $\left(d_{34}\right)$ の 3 つである. 清浄表面について $R_{\mathrm{p}}$ が最小となるように最適化 を行った結果, 5 本の $I-V$ 曲線の $R_{\mathrm{p}}$ の平均が 0.139 と, かな り良い一致が得られた。 その時の $I-V$ 曲線を Fig. 2 に，パ ラメータを Table 1 のCleanの行に示した。誤差は各パラ メータスキャン（Figs. 3(a)-3(c)）の結果を元に, 上記の 計算により $R_{\mathrm{p}} \leq 0.16$ として評価した. Table 1 に示したよう に $d_{12}$ と $d_{23}$ については誤差の範囲でほぼバルクの值であ り, ごくわずかに縮んでいる可能性が高いのに対し， $d_{34}$ は バルクの值よりもわずかに伸びているという結果となった. これは過去に行われたChan らによる動力学的解析結果で $d_{12}=0.216 \mathrm{~nm}$ と最上層間距離が約 $2.6 \%$ 縮むという結果が得 られていたこととは大きく異なっているように見える7).し かし, 彼らの解析は誤差が $\pm 0.01 \mathrm{~nm}$ と我々の結果に比べて はるかに大きく，また $d_{12}$ のみをパラメータとして使用して いたという問題点がある. 我々の結果は $d_{12}$ に関しては彼ら

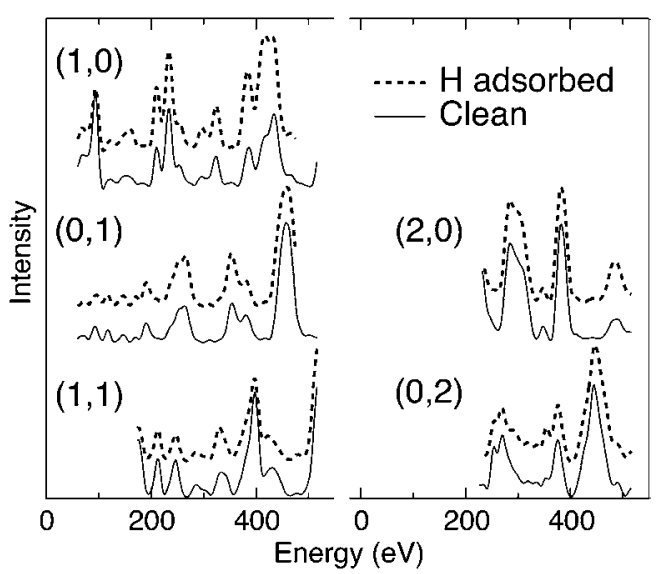

Fig. 1 Comparison between LEED $I-V$ curves for the clean surface (solid lines) and those for the surface after the exposure to $1000 \mathrm{~L} \mathrm{H}_{2}$ (dashed lines). 


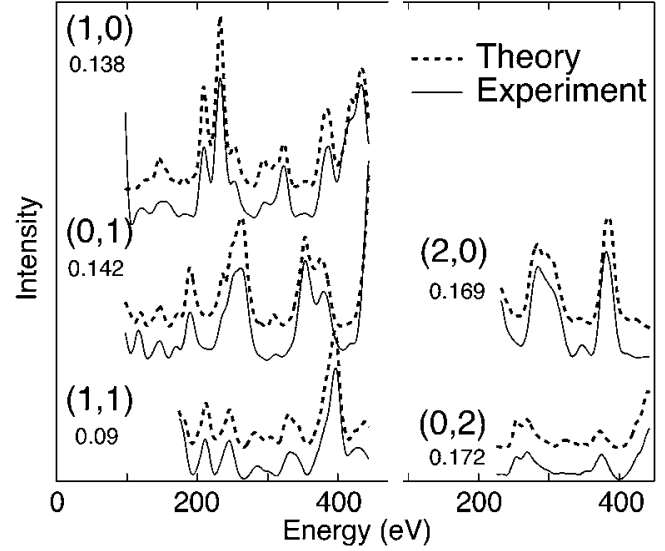

Fig. 2 The result of optimization $\left(R_{\mathrm{p}}=0.139\right)$. Comparison between the experimental (solid lines) and the best theoretical (dashed lines) LEED $I-V$ curves. The numbers below the indices are the $R_{\mathrm{p}}$ values for each curves.

Table 1 The parameteters for the optimized structure for the Clean $\operatorname{Ir}$ (111) and three models for the H-adsorbed Ir (111) surface. The allowed adsorption sites are the ontop, fcc hollow and hcp hollow sites. Bond length of H-Ir, or percentage extension of the layer distance from bulk value are shown in the lower column of each column.

\begin{tabular}{c|c|c|c|c|c}
\hline \hline Model & $\begin{array}{c}d_{\text {H-Ir }}(\mathrm{nm}) \\
\text { bond } \\
\text { length } \\
(\mathrm{nm})\end{array}$ & $\begin{array}{c}d_{12}(\mathrm{~nm}) \\
\text { extention } \\
(\%)\end{array}$ & $\begin{array}{c}d_{23}(\mathrm{~nm}) \\
\text { extention } \\
(\%)\end{array}$ & $\begin{array}{c}d_{34}(\mathrm{~nm}) \\
\text { extention } \\
(\%)\end{array}$ & $R_{\mathrm{p}}$ \\
\hline Clean & & $\begin{array}{c}0.2207 \pm 0.002 \\
-0.45 \pm 0.9\end{array}$ & $\begin{array}{c}0.2202 \pm 0.0025 \\
-0.68 \pm 1.13\end{array}$ & $\begin{array}{c}0.2246 \pm 0.003 \\
+1.31 \pm 1.35\end{array}$ & 0.139 \\
\hline ontop & 0.1233 & $0.2230 \pm 0.0025$ & $0.2212 \pm 0.0033$ & $0.2248 \pm 0.0042$ \\
fcc & 0.1233 & $+0.56 \pm 1.13$ & $-0.24 \pm 1.49$ & $+1.40 \pm 1.89$ & 0.182 \\
\hline \multirow{2}{*}{ hcp } & 0.1025 & 0.2227 & 0.2209 & 0.2249 & 0.179 \\
& 0.1873 & +0.44 & -0.36 & +1.46 & 0.178 \\
\hline
\end{tabular}

の誤差の範囲に入って抢り, Fig. 3(a)-3(c)に示すようにパ ラメータの変化による $R_{\mathrm{p}}$ の変化が大きく, かなり広い領域 に打ける最小值として非常に小さな $R_{\mathrm{p}}$ が得られたことか ら, 実験や解析法の改善による解析精度の向上で, 以前より 誤差の少ない結果が得られたのであろうと考えている.

次に清浄表面の最適構造についての計算結果を水素吸着表 面で測定した実験結果と比較した。すると $R_{\mathrm{p}}$ は 0.1988 に増 大した。これは清浄表面で誤差を評価する際に使用した $R_{\mathrm{p}}$ の值 0.16 よりも大きく, 水素の吸着によって構造に変化が起 きたことを示唆している. そこで, 水素は解離吸着すると仮 定し，その吸着位置として，Fig. $3(\mathbf{g})$ に示したような 1 配 位の ontop site, 3 配位の fcc hollow site, hcp hollow site の 3 つの位置を考えたモデルで, 上の 3 つのパラメータに水素 と最上層の Ir 原子までの距離の表面垂直方向成分 $\left(d_{\mathrm{H}-\mathrm{Ir}}\right)$ を加えて動力学的な解析を行った. 計算の結果得られた最適 構造パラメータを 3 つ吸着位置についてそれぞれ Table 1 に示す。また， $d_{\mathrm{H}-\mathrm{Ir}}$ による $R_{\mathrm{p}}$ の変化を調べた結果を Fig. 3 (d) -3(f)に示す. 最小の $R_{\mathrm{p}}$ が得られたのは hcp hollow site

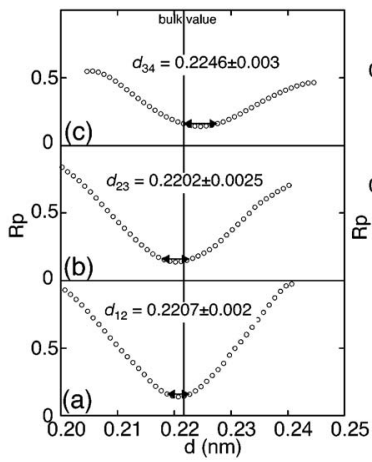

(g) Top View

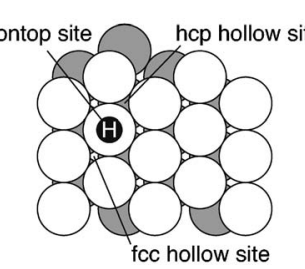

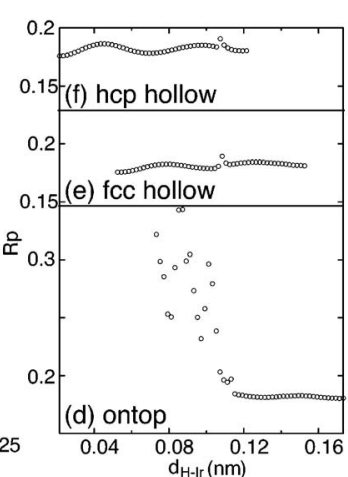

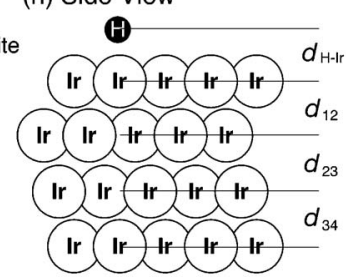

(h) Side View

Fig. 3 (a) - (c) The variations of $R_{\mathrm{p}}$ by (a) $d_{12}$, (b) $d_{23}$, (c) $d_{34}$ for the clean $\operatorname{Ir}(111)$ surface. The arrows show the error bars estimated by the Pendry's method ${ }^{12)}$. A vertical line shows the bulk layer distance. (d)-(f) The variations of $R_{\mathrm{p}}$ by $d_{\mathrm{H}-\mathrm{Ir}}$ for the $\mathrm{H}$ adsorption on the (d) ontop, (e) fcc hollow and (f) hcp hollow sites. $(\mathrm{g})-(\mathrm{h})$ The $(\mathrm{g})$ top and $(\mathrm{h})$ side views of the schematical surface model and the parameters used in the calculation. The three possible adsorption sites are shown in (g).

に吸着した場合であったが，3つの構造モデル間の差は非常 に小さく， $d_{\mathrm{H}-\mathrm{Ir}}$ を変化させたときに $R_{\mathrm{p}}$ があまり変化してい ない. また Table 1 に示した H-Ir 結合長はどれも Ir と H の原子半径の和 $(0.1728 \mathrm{~nm})$ よりもかなり小さい事などか ら, 得られた構造は真の最適構造ではないと考えられる. 特 に ontop site での変化の様子には Ir と H の原子間距離が近 づきすぎたため計算がうまくいかなくなった様子が現れてい る. 従って, 残念ながら今回の結果からは水素の吸着位置を 決定することはできなかった，これは Ir と比べて Hによる 電子の散乱が非常に小さいためであり, 予想された結果では あった．水素吸着による基板の緩和については Table 1 に示 されているように水素の吸着位置によらず同じ傾向の結果が 得られており, 水素の吸着による $I-V$ 曲線の変化は主に基 板の緩和により引起こされていることが分かる. 結果は第 1 層が少し外側に伸びて層間距離がバルクの值よりもわずかに 大きくなる事を示しているが，伸びは非常に小さく，誤差の 範囲ではバルクの值から変化していないと言える. 以上のこ とから Ir (111) 清浄表面抢よび水素吸着表面についてはどち らも緩和の大きさは非常に小さく, ほぼバルクの構造を保持 しているということが結論できる。これは $\mathrm{Ni}(111)$ 面4) や Ir (100)面5,6)で, 水素の吸着により表面再構成が起きて基板最 上層が大きくバックリングしていることとは非常に対照的で $\operatorname{Ir}(111)$ 表面の安定性を示していると言える.

最後に水素吸着表面で得られた $R_{\mathrm{p}}$ が清浄表面と比べて高 い原因について考察する. 0.18 という值は LEED の構造解 析結果としては十分小さな值ではあるが, LEEDの構造解 析には考慮したモデル以外についての情報は全く得られない 
という避けられない欠点がある. 今回の計算で考慮したモデ ルは他の研究を参考にして仮定した $1 \times 1$ 構造から考えられ る最も一般的なもののみである1,2).これらのモデルの中に 決定的なものは存在しなかったが, 全く異なる構造モデルが 正しいという可能性は捨てきれない。 またもう一つの可能性 として水素の非局在化による影響が考えられる. Hagedorn らは低被覆率領域で水素が非局在化している可能性を指摘し たが，本研究で測定した高被覆率領域に颃いても幅の広い ピークが HREELS で観察されているため1)，これらの水素 が LEEDの解析に影響を与えている可能性がある. 現在の LEED パッケージでは非局在化した原子による電子散乱は 考慮されていないため, 正確な構造解析を行うには理論面か らの研究も必要である.

\section{4. 結論}

$\operatorname{Ir}(111)$ 清浄表面および水素吸着表面について LEED の $I-$ $V$ 曲線を測定し, CLEED パッケージを用いた動力学的解析 を行った. 清浄表面については, 過去の報告より高精度の構 造解析を行い, 最表面層の原子はほとんど動いていないかわ ずかに内側に緩和していることを示した．また，水素吸着表 面については，水素の位置の決定はできなかったが，基板の 緩和を調べ，最上層原子が水素の吸着によりわずかに外へ動 いているものの, その移動量は非常に小さいことがわかっ た. $\operatorname{Ir}(111)$ 面は水素の吸着によりほとんど変化しない安定 な表面であると考えられる。

\section{謝辞}

CLEED プログラムを提供し, 計算に関する助言を与えて くださった G. Held 博士に感謝します.

\section{〔文献〕}

1) C. J. Hagedorn, M. J. Weiss and W. H. Weinberg: Phys. Rev., B 60 (1999) R14016.

2) 中西 寛, 笠井秀明, 福谷克之, 岡田美智雄 : 日本物理学会 2005年秋季大会予稿集第 4 分冊, p726.

3) M. Arnold, G. Hupfauer, P. Bayer, L. Hammer, K. Heinz, B. Kohler and M. Scheffler: Surf. Sci., 382 (1997) 288.

4) L. Hammer, H. Landskron, W. Nicht-Pecher, A. Fricke, K. Heinz and K. Müller: Phys. Rev., B 47 (1993) 15969.

5) K. Heinz and L. Hammer: J. Phys. Chem. B, 108 (2004) 14579.

6) L. Hammer, W. Meier, A. Klein, P. Landfried, A. Schmidt and K. Heinz: Phys. Rev. Lett., 91 (2003) 156101.

7) C. M. Chan, S. L. Cunningham, M. A. VanHove, W. H. Weinberg and S. P. Withrow: Surf. Sci., 66 (1977) 394.

8) M. Okada, K. Moritani, T. Kasai, W. A. Dino, H. Kasai, S. Ogura, M. Wilde and K. Fukutani: Phys. Rev., B 71 (2005) 033408.

9）岡田美智雄, 笠井俊夫, 小倉正平, Markus Wilde, 福谷克 之, 信原邦啓, 中西寛, Wilson Agerico Dinõ, 笠井秀明 : 日本 物理学会2004年秋期大会予稿集第 4 分冊, p784.

10) G. Held and W. Braun: http://www.ch.cam.ac.uk/staff/ gh.html.

11) A. Barbieri and M. A. Van Hove: http://electron.lbl.gov/ software

12) J. B. Pendry: J. Phys. C: Solid St. Phys., 13 (1980) 937.

13）国立天文台編：理科年表2000, 丸善株式会社. 